two soils in pots. The specific activity of calcium absorbed by barley and ryegrass fell steadily during growth owing to a slow equilibration with forms of calcium other than exchangeable calcium. As roots locally depleted supplies of labile calcium, more calcium came into circulation. Exchangeable and available calcium can no longer be regarded as synonymous, and the latter is affected by the activities of plant roots.

Dr. R. Scott Russell (Agricultural Research Council Radiobiological Laboratory) directed attention to different steps in nutrient absorption by roots and stressed that the effective area of absorption was restricted to a region near the apices. The availability of a nutrient to a plant may be influenced by interactions with other ions either by competition or by physiological changes. Dr. Seott Russell referred to work which suggested that the individual root-absorption characteristics of different crops influenced the apparent availability of a nutrient such as phosphorus in a soil.

The probable parts played by micro-organisms were described by Mr. J. S. Waid (Levington Research Station, Ipswich), who stressed that much of the evidence was circumstantial and required further substantiation. Organisms are known to be able to increase the water solubility of nutrients by oxidation or reduction, and by the decomposition of organic materials; the availability of nitrogen is intimately bound up with biological processes. Soil organisms may compete with roots for soluble nutrients especially when stimulated by supplies of organic materials, some of which may be provided by the roots themselves; production of carbon dioxide or toxins may affect the physiological activity of plant roots.

Dr. G. W. Cooke's paper (Rothamsted Experimental Station) described the problems of assessing the nutrient status of a soil for advisory purposes : here the criterion is the probable economic response of various crops to fertilizer dressings, and in this field soil analysis has not made much progress. The results generally distinguish between the broad levels of nutrient status for phosphorus and potassium, but in order to avoid crop failure in the exceptional cases the overall application of these fertilizers is about double the amount that is economically justified. The assessment of the nitrogen status of soils is even more uncertain, and there is an acute need for the development of fresh analytical techniques tested against field trials. Dr. Cooke suggested that a more successful approach might lie in the use of soil analysis for 'fertility control' whereby a record was maintained of the fertility status of a soil so that warning was given of abnormalities before they became acute.

In the open discussion which followed these papers the following points were among those made.

Correlation between soil analyses and field responses is poorer in tropical and other under-developed areas than it is in Britain, yet the need for reliable soil tests is even greater. Different speakers stressed the importance of studying the anomalous soils in order to discover which factors affecting the availability of nutrients have been neglected. Analysis should not be divorced from examination of profiles since often these showed some physical property which meant that, while nutrients might be available in the chemical sense, they were inaccessible to plant. roots.

The value of plant analysis in relation to fruit crops and forestry was mentioned; by this means it may be easier to recognize an interaction effect which is not revealed by soil analysis. Some progress was also reported on the development of techniques for determining the nitrogen status of soils: this seems to be greatly affected by re-wetting of air-dry samples.
D. V. CrawFord

\title{
AHMEDABAD MILLOWNERS' TEXTILE INDUSTRY'S RESEARCH ASSOCIATION
}

A TEXTILE research laboratory, created and sustained by the co-operative effort of the industry and the Government of India, was envisaged by the Ahmedabad Millowners' Association as early as 1944. In 1947, the Ahmedabad Textile Industry's Research Association was registered with a membership of seventy-one mills. Ahmedabad thus became the proud pioneer in establishing a co-operative research centre for the cotton textile industry in India.

The Association started functioning in 1949, and its impact was soon felt by the industry in and around Ahmedabad. It became clear to the original members that the benefits accruing from research could with advantage be placed at the disposal of the industry on a nation-wide basis. With this object in view, the constitution of the Association was suitably amended so that mills outside Ahmedabad could become members and enjoy the same research benefits as the original founders. The present strength of members including all categories stands at eighty-eight mills and allied concerns, comprising thirty lakhs of spindles and sixty-three thousand looms-roughly one-third of the Indian cotton textile industry.

The policies of the Association are decided by an autonomous body known as the Council of Adminis- tration. At present, the twenty-member Council is made up of representatives of management, nominees of the Government of India, the director and secretary of the Association as well as directors of other research organizations, and co-opted scientists. The Textile Commissioner is one of the nominees of the Government of India. Shri Kasturbhai Lalbhai has been the chairman of the Council from its inception.

The composition of the Council ensures a balanced and co-ordinated research policy which takes into account similar efforts by other textile research institutions and national laboratories. Further links with Government and with national research in related spheres have been established through the Ministry of Scientific Research and Cultural Affairs.

The Association began modestly in 1949 in three rooms in the Mafatlal Gazalbhai Science Institute. The foundation stone of the present building, which is housed on a 50-acre campus to the west of Gujarat University, was laid by Sardar Vallabhbhai Patel in November 1950 . The building was completed towards the end of 1953 and formally declared open by Shri Jawaharlal Nehru in April 1954. 
The laboratories of the Association are equipped with instruments for research in textiles and allied fields. Some of these instruments have been designed and fabricated there. The physics laboratory has equipment for studying the structure and physical and mechanical properties of fibres, yarns and fabrics. The chemistry laboratory has, in addition to the usual facilities for analysis of textile materials, a unit processing section equipped for the treatment of samples of yarns and fabrics through processes such as bleaching, dyeing, printing and finishing. The pilot mill is a versatile unit and its machinery offers a wide range of processing sequences in spinning, weaving and chemical processing. The workshops are equipped for the dual purpose of servicing mill machinery and of designing, fabricating and servicing laboratory instruments.

The Association owes its success in large measure to the enthusiasm of its workers. Most of these workers have been recruited from universities and initiated into specialized fields of industrial research. When necessary, training has been supplemented by periods of study in overseas institutions. Technical assistance schemes such as the Point Four Programme, the Colombo Plan and the Imperial Chemical Industries Fellowships have been of great value. From a small group of about twenty-five workers in 1949, the Association has developed into an organization with a total strength of 200 , which is made up of 75 scientists and technologists, 25 administrative workers, 40 skilled operatives and 60 service personnel.
The services of a number of foreign specialists have been secured from time to time with the assistance of organizations like Unesco and the International Labour Organization; in 1956 the Association was recognized by Gujarat University as a teaching centre for postgraduate research. At present most of the research students are awarded scholarships or fellowships by the Government of India, the Council of Scientific and Industrial Research, Gujarat University and the Association.

In a technologically under-developed country, it is often the path of least resistance to apply to one's own use the findings of more advanced countries. During the early days, the Association emphasized the application of scientific and technical knowledge already available to the problems of the industry. This practice of helping the industry to implement the findings of research has paid rich dividends and constitutes one of the main activities of the Association at present. In the process, industry has become wide awake to the potentialities of original research and has cordially welcomed the Association's efforts.

While being primarily a research organization the Association tries to help industry in other ways. Training in various skills, such as management and supervision, statistical methodology and testing procedures, is given to the staffs of member mills. Such trained personnel not only become better equipped for their work, but also help in securing more effective implementation of the Association's programmes. Often, they form the nucleus of research and training groups in their own organizations.

\section{GLASSHOUSE CROPS RESEARCH INSTITUTE}

$\mathrm{T}$ HE annual report of the Glasshouse Crops Research Institute for 1957* shows that, although full facilities are not yet available, the physical development of the Institute has made good progress and some of the major problems associated with commercial glasshouse practice have been investigated. Physiological studies of the growth of tomatoes have continued, and practical problems of plant spacing and pruning have received attention. Previous studies at Cheshunt and the Institute havn shown that retention of lateral branches below the first truss, on widely spaced plants, of the variety 'Potentate' gave a yield nearly three times as great as on single-stemmed plants. It was of importance to discover whether this constituted an increase in yield per unit area of glasshouse space, the factor of most concern to the grower. This has been investigated in preliminary experiments by comparing the yields from plants having no side shoots and plants in which side shoots below the first truss had been allowed to develop. Three different spacings between the rows were used. The greatest yield per unit area was obtained from single-stemmed plants at the two closest spacings, namely, $2 \mathrm{ft}$. and $3 \mathrm{ft}$., although multistemmed plants at $3 \mathrm{ft}$. and $4 \mathrm{ft}$. spacings had the greatest mean weight of individual fruit. No treatment had any effect on weight per unit area of early fruit.

A review of the literature on spacing of tomato plants in commercial cultivation, included in the report, shows that there is no simple answer to the

* Glasshouse Crops Research Institute. Annual Report 1957. Pp. 161. (Littlehampton: GIasshouse Crops fiesearch (nstitute, 1958.) 108. question of optimal planting density for maximum yield. It is thought that this may be because in. sufficient attention has been given to possible interactions between planting density and watering and manuring. The study of the composition of the tomato fruit has been continued by the Chemistry Department, especially in relation to variety and state of ripeness of the fruit, with special reference to fruit quality and ripening disorders. It was concluded that the latter, evident by their effects on the outer fruit wall, were also related to the composition of the inner portion of the fruit. Further investigations were made of the changes during ripening. The acidity in the wall increased from the green stage to the first appearance of yellow pigmentation, but there was no consistent trend as ripening proceeded. This was in contrast to the situation in the inner portion of the fruit, where acidity decreased and sugars (mainly glucose and fructose) increased. The concentration of soluble solids in the expressed sap of the tomato varies considerably in relation to fruit quality and variety. These investigations will be facilitated by the demonstration that measurement of refractive index by a simple hand refractometer gives a reliable indication of total dissolved solids.

Work on urea-formaldehyde compounds as slowacting nitrogenous fertilizers has been concluded, and a report gives the relative merits of the several compounds tested. Liquid feeding of tomatoes is of considerable topical interest, especially in connexion with automatic irrigation, and research on this problem has been resumed. Magnesium deficiency 